\title{
SKIN ARTHROPLASTY AS A POSSIBLE MEANS OF MOBILISING A TUBERCULOUS HIP
}

\author{
A. G. Karlen, Stockholm, Sweden, and D. R. Gunn, Singapore
}

To achieve a successful arthroplasty has been one of the great objectives of orthopaedic surgeons for many years and an excellent review of this subject was made by Kallio (1958). Loewe (1929) reported the use of skin for arthroplasty of the hip. It has also been used for arthroplasty of finger joints by Pais (1948), and there have been several other similar reports. Kallio (1955, 1957 $a$ and $b$ ) reported a considerable experience of skin as an interposition material in arthroplasty of the hip.

That tuberculosis of the hip has rarely been treated by arthroplasty is shown by a review of the relevant literature; Putti (1921) said that an arthroplasty was unsuitable for children or for old people and that arthrodesis was to be considered the best treatment for tuberculous arthritis. Campbell (1921) also believed that no attempt should be made to mobilise tuberculous joints. Hoover and Coventry (1961) said that a skin membrane did not survive in the hip joints of dogs or contribute to the formation of new articular surfaces, but previously Kettunen (1956) had found that, when used in the hip of cats, metaplastic fibrocartilage resulted.

In 1958 one of the authors (A. G. K.) attempted the mobilisation of one hip in a child in whom tuberculous and secondary infection had caused bony ankylosis of both hips. The result was encouraging and in 1960 a preliminary report on the first seven cases was presented (Karlen 1960). Eighteen cases have now been treated by skin arthroplasty and it is felt that sufficient time has elapsed to attempt to evaluate this procedure.

\section{MATERIAL}

Most of the patients operated on were children, of whom the youngest was five and the oldest eleven years old. There was one patient aged twenty-two years. The average age of the children was eight. At first the procedure was used only for children with ankylosis of both hips but, as experience was gained, the operation was done on others with unilateral tuberculous arthritis of the hip.

Preliminary treatment-The early cases had all been under treatment for tuberculosis for long periods but at the time of operation the disease was regarded as being both clinically and radiologically inactive. This policy has been continued throughout the series although the delay between primary treatment and arthroplasty has been reduced to as little as six months in some of the later cases. When a child is first seen with a hip badly destroyed by tuberculosis it has now become usual to explore the hip and do an extensive clearance as soon as possible. A high erythrocyte sedimentation rate is regarded as an indication for early surgery. After clearance the hip is immobilised in a plaster spica for three months or more. If at that time the hip remains painful a new spica is applied, but if there is no pain the child is left free in bed. If, as usually happens, this regime results in a fibrous ankylosis of the joint, a skin arthroplasty is done, but only if the hip has remained painless for three to six months, that is, six to nine months after the first operation.

\section{TECHNIQUE OF SKIN ARTHROPLASTY}

Operation-Various exposures of the hip joint have been used, and the technique used in this series was that described by Kallio (1955). After dislocation of the hip joint both the acetabulum and the upper end of the femur are trimmed down to healthy bleeding bone. The 
upper end of the femur is then shaped to fit the acetabulum as well as possible: this may require an extensive exposure. A circle of full thickness skin with a layer of subcutaneous fat is then removed from the abdominal wall and is used to cover the upper end of the femur. It does not seem to be important which surface of the skin is opposed to the acetabulum. The skin is held in place by a purse-string suture and also by two transfixion sutures through the neck of the femur at right angles to one another.

Treatment after operation-After operation the patients were either immobilised in a hip spica or on a Robert Jones frame with skin traction to both legs; there is no doubt that the latter is the more satisfactory procedure.

Passive movements of the hip were begun at two weeks, active movements at four weeks, and weight bearing was allowed at eight to ten weeks.

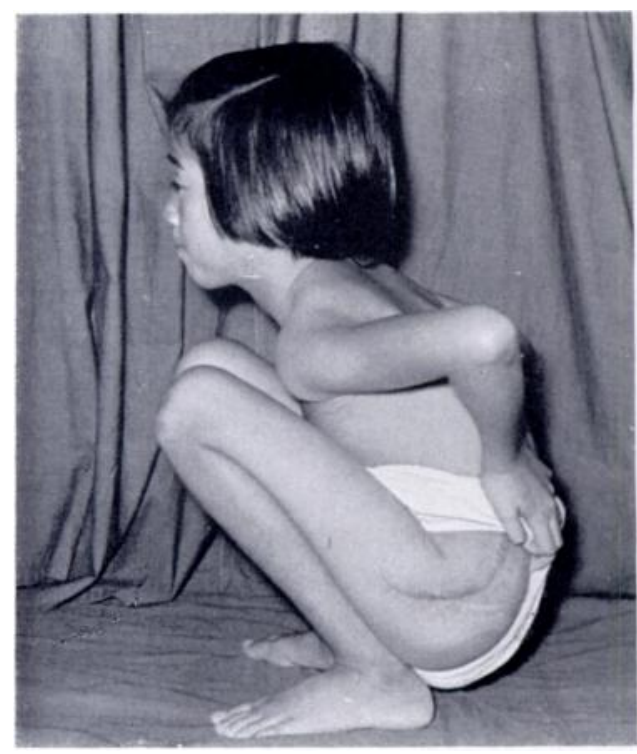

Fig. 1

A child who had had a skin arthroplasty on the left hip three years before.

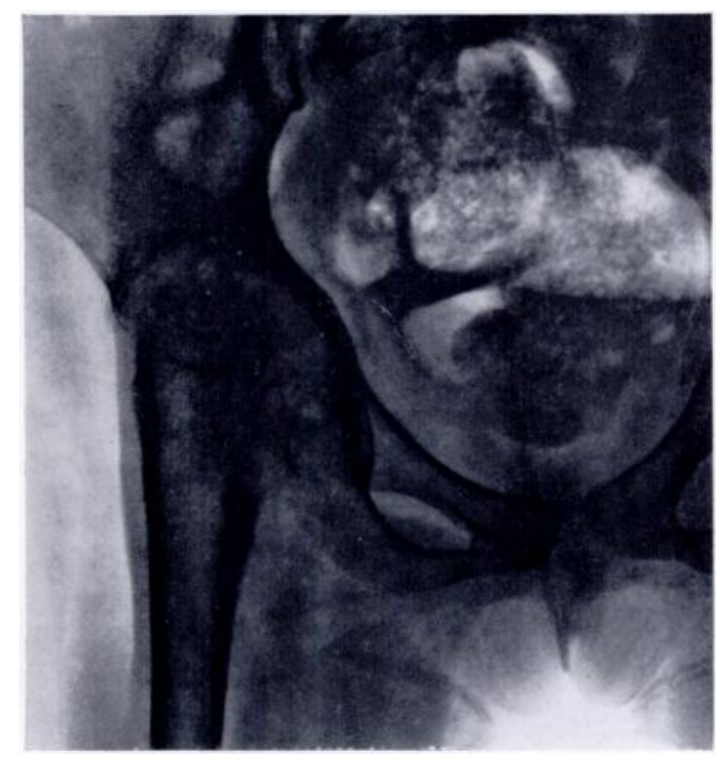

Fig. 2

Three attempts to fuse this tuberculous right hip had failed: this is an early radiograph after a skin arthroplasty had been done.

\section{RESULTS}

Of the eighteen patients that have been followed up, the one adult was excluded because the arthroplasty failed and the pain in the hip necessitated arthrodesis.

The seventeen remaining patients, all between the ages of five and twelve at operation, were followed up for an average period of three years (Fig. 1).

The best results were those in which a painless, stable hip with a nearly normal range of movement was produced. The worst results were ankylosis.

Six patients had a range of flexion and extension of 90 degrees or more, with a useful range of rotation, abduction and adduction. Radiologically these hips showed improvement, with the formation of a wide joint space and the development of a well defined acetabular roof (Figs. 2 to 6 ).

Six hips had a painless range of flexion and extension varying from 15 to 80 degrees; most had a useful range of rotation and abduction, and all were stable. Three hips developed fibrous ankylosis and two hips fused by bone.

Complications-The main complication has been the development of a stiff hip, from bony or fibrous ankylosis. Two hips became septic: one was in the only adult; the second was in a child in whom the end result was a fibrous ankylosis.

VOL. $48 \mathrm{~B}$, No. 3, AUGUST 1966 


\section{DISCUSSION}

In south-east Asia an ankylosed hip is a far greater disability than it would be in Europe or America; squatting is a normal and much used position and the inability to squat is a serious handicap. Arthrodesis of a tuberculous hip is, therefore, not readily accepted by patients.

In an attempt to produce a mobile hip joint after severe tuberculous destruction skin arthroplasty has been moderately successful. Two-thirds of the patients have some painless movement in the hip in which even a small range of flexion and extension is important.

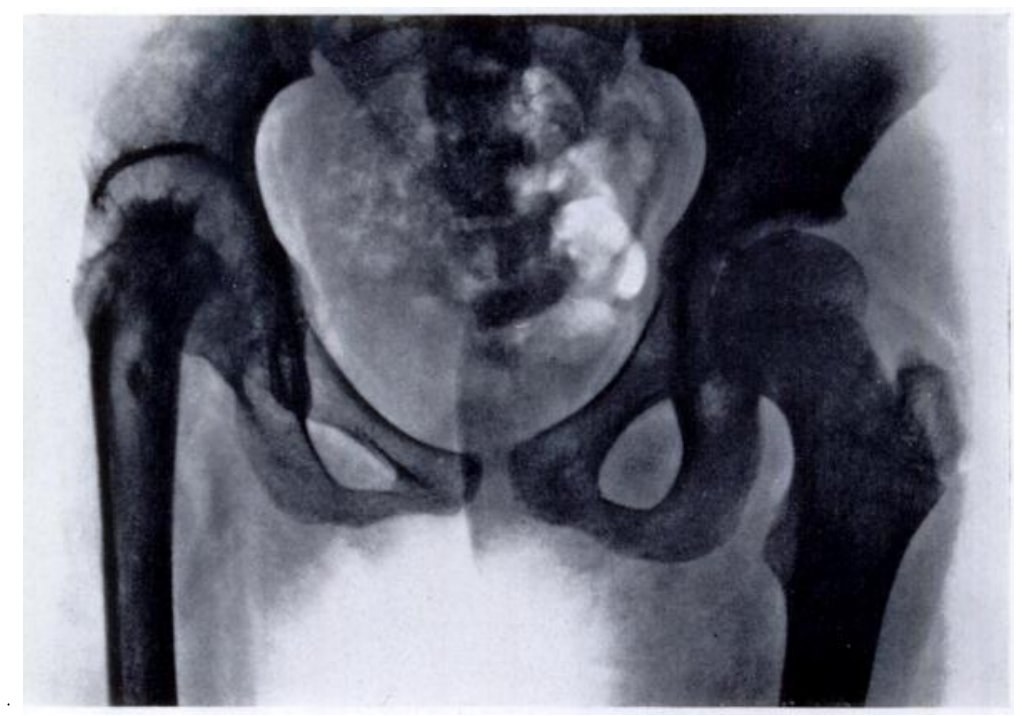

FIG. 3

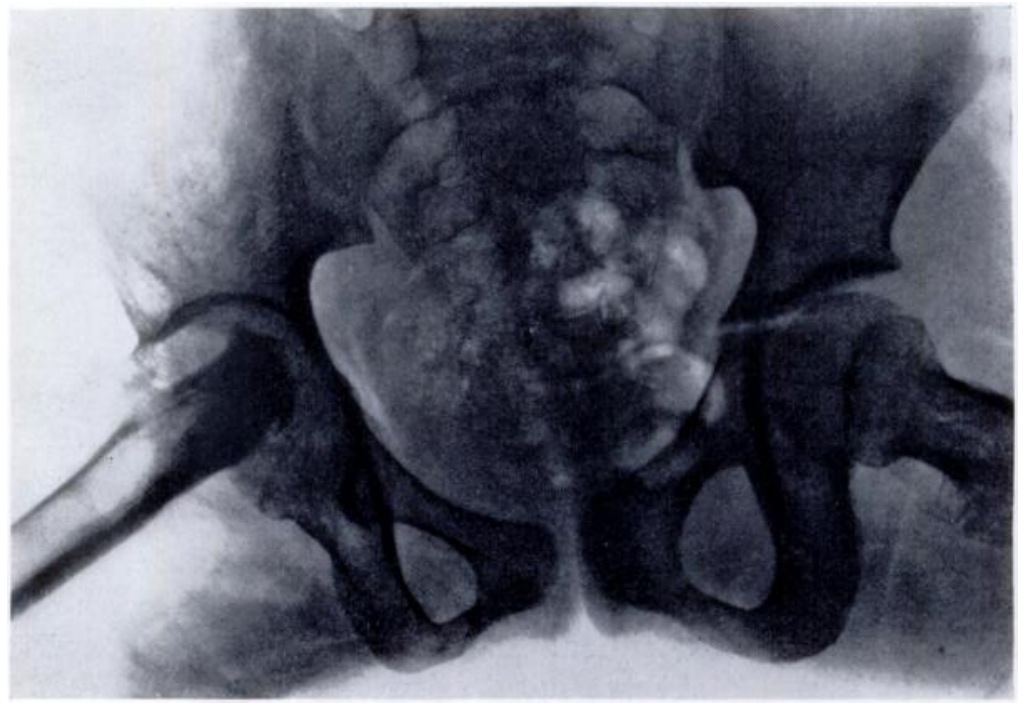

Fig. 4

The same case as in Figure 2 two years later. Approximately 80 per cent of the normal range of movement was present then, with no pain, and the condition remains the same.

In the worst results a fibrous ankylosis has been achieved and a formal arthrodesis may be required at a later date. Because only a small amount of bone is removed a previous skin arthroplasty does not jeopardise the chance of a successful arthrodesis. 


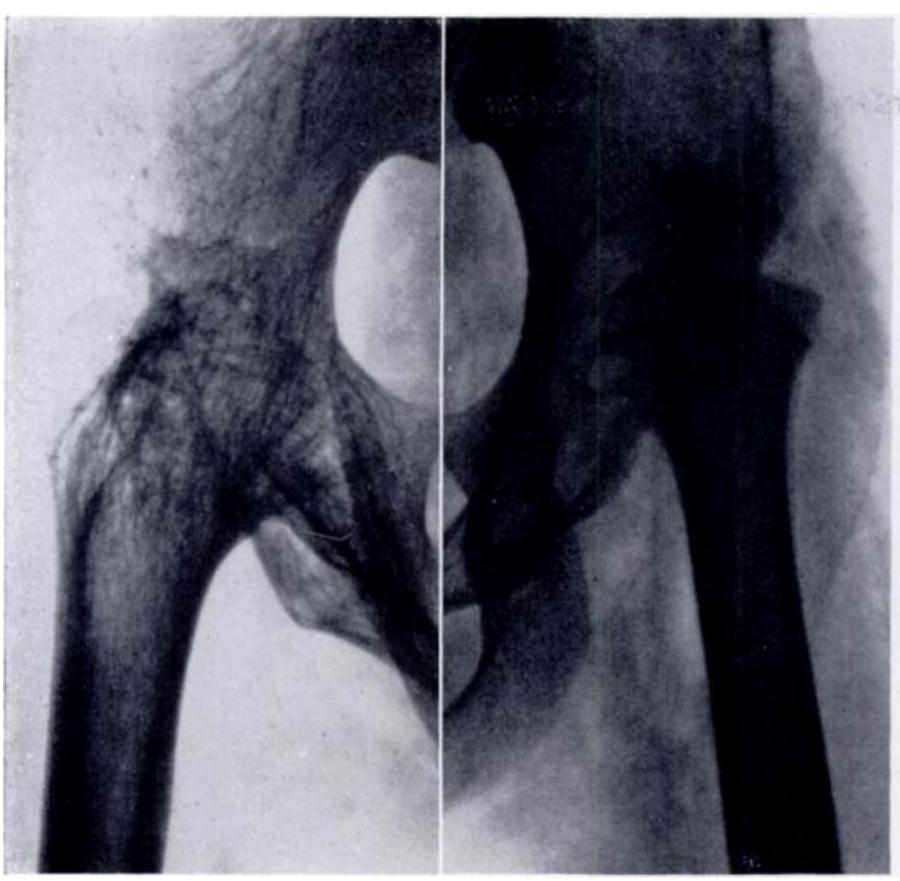

Fig. 5

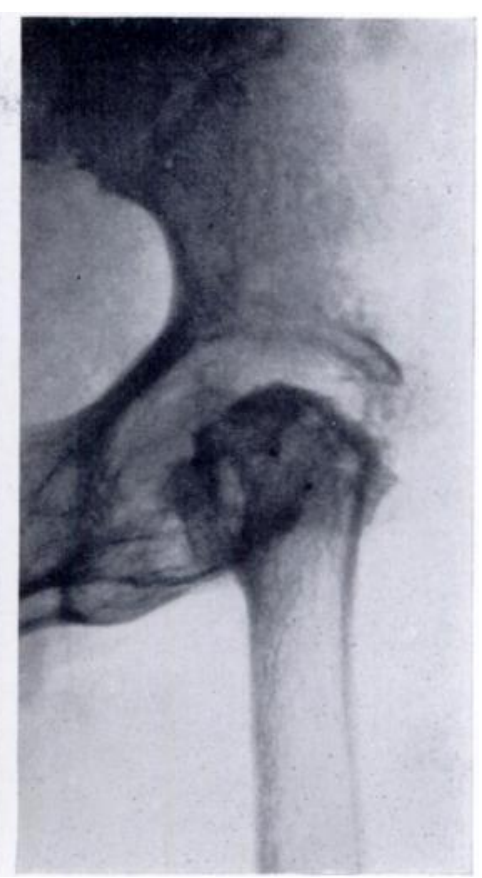

FiG. 6

This child had bony ankylosis of both hips. A skin arthroplasty was done. The radiograph in Figure 6 was taken five years later. There was 80 per cent of painless flexion and excellent rotation.

\section{SUMMARY}

1. In seventeen cases of tuberculosis of the hip in children with severe destruction of the joint arthroplasty was done using full thickness skin from the abdominal wall as the interposing material.

2. The results, after a follow-up on the average of three years, show that one-third of the cases are very satisfactory, one-third are fair and one-third show no movement.

\section{REFERENCES}

Campbell, W. C. (1921): Arthroplasty of the Knee-Report of Cases. Journal of Orthopaedic Surgery, 3, 430. Hoover, N. W., and Coventry, M. B. (1961): Skin Arthroplasty of the Hip. An Experimental Study in Dogs. Journal of Bone and Joint Surgery, 43-A, 1155.

Kallio, K. E. (1955): Arthroplastic cutanée de la hanche. Auto-greffe fraiche de peau totale avec tissu adipeux. Mémoires de l'Académie de Chirurgie, 81, 458.

Kallio, K. E. (1957a): Arthroplastia Cutanea. Acta Orthopaedica Scandinarica, 26, 327.

Kalı.1O, K. E. (1957b): Fresh Whole-Thickness Skin Autograft with Adipose Tissue as Interposition Material in Arthroplasty. Year Book of Orthopaedics and Traumatic Surgery, 1956-1957, p. 210. Chicago: The Year Book Publishers Incorporated.

Kal.L.o, E. (1958): Skin Arthroplasty of the Hip Joint and Corresponding Alloplastic Methods in the Light of a Clinical Study. Acta Orthopaedica Scandinavica, Supplementum 30.

KarLeN, A. G. (1960): (Unpublished.)

Kettunen, K. (1956): Changes in the Fresh Autogenous Whole-thickness Skin Graft Used as Interposition Material in Arthroplasty of the Hip Joint on Cats. Annales Chirurgiae et Gynaecologiae Fenniae, 45, 193.

LOEWE, O. (1929): Ueber Haut-Tiefenplastik. Mïnchener Medizinische Wochenschrift, 76, 2125.

Pals, C. (1948): Arthroplastica delle dita con interposizione di lembo cutaneo. Atti del XXXIII Congresso dell Società Italiana di Ortopedia e Traumatologica, 157.

Putri, V. (1921): Arthroplasty. Journal of Orthopaedic Surgery, 3, 421. 